Savunma Bilimleri Dergisi

The Journal of Defense Sciences

Kasım/Nov 2018, Cilt/Volume 17, Sayı/Issue 2.

ISSN (Bas111) : 1303-6831 ISSN (Online): 2148-1776

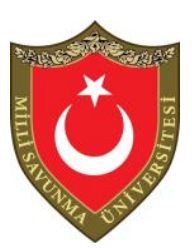

\title{
Jeomanyetik Firtınaların Pilotların Kognitif Durumlarına Etkileri Üzerine Hipotez
}

\author{
Ümit Deniz Göker*
}

$\ddot{O} z$

Pilotlar gibi bilişsel (kognitif) yeteneği gelişmiş, hareketlerinde kuvvetli bir kararlıllğa sahip ve görevinde ya da tehlikeli durumlarda izleyeceği doğru adımları bilmesi gibi sinirsel uyarımlarını etkileyen tüm bilişsel ve kişilik (personality) psikolojisi testlerinin tamamını başarıyla geçmiş kişilerde organik süreçler kusursuz işlemektedir. Havacılık Psikolojisi, uçuşun uçuş personeli ve yolcular üzerindeki fiziksel ve zihinsel etkileriyle ilgilenen bilim dalıdir. Belli dönemlerde dünya manyetosferinin düzenini bozucu etkiye sahip olan jeomanyetik firtınalar gibi astronomik olaylar, bu organik süreçler üzerinde halsizlik, keyifsizlik ve sebebi belli olmayan bölgesel baş ağrılart, hareket fonksiyonlarında düzensizlik, denge bozukluğu, kalpte enfarktüs, nöbet durumlarl ve sinir sistemine bağll ruhsal bozukluklar gibi negatif etkilere sebep olacaktır. Bu makalede, jeomanyetik firtınalarla ilgili önceki çalışmaların verdiği sonuçlar ile nörofizyolojik araştırma sonuçlarından yola çıkarak, jeomanyetik firtınaların etkisinin beyin ve sinir sisteminde yapması beklenen hasarlar belirtilmiştir. Bu etkilerin incelendiği laboratuvarların Türkiye'de kurulması halinde olası yapılabilecek psikolojik ve medikal deneylerin uygulama yöntemleri de makalede ayrıca verilmiştir. Yüksek enlemlerde uçan pilot ve uçuş ekibi, jeomanyetik firtınanın etkisini birebir yaşayacaktır; hâlbuki Türkiye gibi orta enlemlerde hava taşıtı kullanan pilot ve uçuş ekibinin ancak laboratuvar ortaminda test edilerek, bu etkilere verdikleri tepkiler ölçülebilir. Bahsi geçen bu deneylerin havacılık psikolojisi literatüründe ilk kez uygulanacak olması nedeniyle de bu hipotez ayrı bir önem taşımaktadır.

Anahtar Kelimeler: Jeomanyetik Firtınalar, Havacılık Psikolojisi, Kognitif Psikoloji, Insan Beyni, Sinir Sistemi.

\footnotetext{
* Dr.Öğr.Üyesi Ümit Deniz Göker, İstanbul Gelişim Üniversitesi, İktisadi İdari ve Sosyal Bilimler Fakültesi, Havacılık Yönetimi Bölümü, E-mail: udenizg @ gmail.com

Geliş Tarihi/Received:07.08.2018

Kabul Tarihi/Accepted:08.08.2018
} 


\title{
Hypothesis on the Effects of Geomagnetic Storms on Cognitive States of Pilots
}

\begin{abstract}
The organic processes work flawlessly in those who have successfully completed all the tests of cognitive and personality psychology, such as pilots. Pilots with cognitive abilities have a strong commitment to their movements, and they influence their neural stimulation, such as the ability to acknowledge the right steps to follow in their task or in dangerous situations. Aviation Psychology deals with the physical and mental effects of flight on aircrew personnel and passengers. Astronomical events, such as geomagnetic storms that have a disruptive effect on Earth's magnetosphere in certain periods, will cause negative effects, such as weakness, malaise and unspecified regional headaches, irregularity in movement functions, misbalance, heart infarction, seizure situations and mental disorders due to the nervous system, on these organic processes. This article describes the expected damages to the brain and nervous system caused by the effects of geomagnetic storms, based on the results of previous studies on geomagnetic storms and neurophysiological studies. Application methods of the possible psychological and medical experiments in case of the laboratories to be established in Turkey are also given in this article. The pilot and flight crew flying at high latitudes will experience the effect of the geomagnetic storm directly; whereas the response of the pilot and flight crew using the aircraft in the middle latitudes, such as Turkey, to these effects can be measured only with tests in the laboratory environment. This hypothesis has a special importance, as these experiments will be applied for the first time in aviation psychology literature.
\end{abstract}

Keywords: Geomagnetic Storms, Aviation Psychology, Cognitive Psychology, Human Brain, Nervous System.

\section{Giriş}

İnsan davranışlarının temelinde bazı organik süreçler işlemektedir. Beyinde oluşan bu organik süreçler, kaslara geçerek sonrasında sergilenen davranışlar olarak dışarı yansır (Cüceloğlu, 1999). Havanın basınc1, 1sısı veya nemi gibi 
çevresel değişiklikler, vücuttaki nörobiyokimyasal olayları etkiler ve bu nörobiyokimyasal değişikler neticesinde ortaya çıkan davranışlarımız da nörofizyolojik olarak incelenebilmektedir (Cüceloğlu, 1999). Sinirsel uyarımlar, nöron adı verilen sinir hücreleri ile kendisine aktarılan bilgiyi elektriksel ve kimyasal bir ağdan işleyerek beyne aktarır ve beyin ise gelen bu bilgiye karşılık uygun motor reaksiyonu uygular. Genelde bu reaksiyon 0,1 ilâ 0,2 saniye arasında değişir. Bununla birlikte, ses hızının üç katı hızdayken bir jet pilotunun bir durumu idrak etmesi için 1,5-2 saniye gerekir (Gagarin ve Lebedev, 1984).

Bir kişinin pilot olabilmesi için bilişsel yetenekleri gelişmiş, hareketlerinde kuvvetli bir kararlılığa sahip ve görevinde ya da tehlikeli durumlarda izleyeceği doğru adımları bilmesi gibi sinirsel uyarımlarını etkileyen tüm bilişsel ve kişilik psikoloji testlerinin tamamını başarıyla geçmiş olması gerekmektedir (Ragan, 2010). Pilotun bilişsel yeteneklerinin, hız kombinasyonu ve bilgi işlemesindeki kesinliği sağlama başarısında, çok büyük bir rolü olmaktadır. İkinci önemli durum ise pilotun cesaret, öz disiplin, öfke kontrolü yapabilme, özgüven sahibi ve büyük risk içeren durumlarla başa çıkabilme yeteneği gibi kişilik özelliklerine sahip olmasidir (Ragan, 2010).

"Bilişsel psikoloji (cognitive psychology), algilama, bellek ve bilgi işlem süreçlerini inceleyen bilim dalı olup organizmanın içinde yer alan bilişsel süreçlerin türü ve yapısıyla, gözlenebilen davranışların türü ve özellikleri arasındaki ilişkiyi araştırır. Kişilik psikolojisi (personality psychology) ise bireylerin kendilerine özgü davranış, düşünce ve duygu biçimleriyle ilgilenir" (Cüceloğlu, 1999: s.29 ve s.37).

Havacılık psikolojisinin tarihsel gelişimine bu başlık altında kısaca değindikten sonra, diğer başlıklarda jeomanyetik firtına gibi çok önemli bir meteorolojik (hatta astronomik) olayın pilotların uçuşunu nasıl etkilediğini ve bu etkinin nörofiziksel olarak nasıl ele alınacağına değineceğiz.

En yaygın anlamında "Havacılık Psikolojisi”, uçuş ekibinin performansları, ekibin desteklenmesi, varsa yolcular, hava trafik kontrol sistemindeki idareciler ve kontrol ekibi, havayolu personeli ve diğer tüm sorumlu kişileri ve uçağa ilişkin tüm tasarım ve bakım işinden sorumlu kişiler gibi genel havacılığa ilişkin tüm bilgilere göre insanların bu bilgiler karşısında gösterdikleri davranışsal becerilerini ve 
sınırlarını temel alarak uygulanmasını içermektedir (Koonce, 1984). Diğer bir değişle havacılık psikolojisi, uçan insanı anlamaya çalışmaktan başlayıp uçucu adayı seçiminde doğru insanları bulmak için testler ve mülâkatlar yapmaya, uçucuların riskli düşünüş ve davranışlarına ve psikiyatrik bozukluklarına çözüm üretmeye kadar geniş bir yelpazede kilit ve/veya anahtar rolü olan bir bilimdir (Çetingüç, 2016). Yüzyıllar öncesine dayanan uçma denemelerine karşın yirminci yüzyılın erken zamanlarında gelişen havacılık, pilotların becerileri ve pilotlar üzerinde meydana gelen yeni çevresel etkiler, ilk havacılık psikologlarının ortaya çıkmasına neden olmuştur. Bu kişiler, ilk zamanlarda tıp, psikoloji ve fizyoloji alanlarında eğitim almış kişilerden oluşmakta olup; erken dönemlerde bu işlerle uğraşan kişiler yaygın bir şekilde uçma becerisi edinme, benzersiz kavrama gereksinimleri ve fiziksel streslerin incelenmesi gibi psikofiziksel uygulamalara hitap etmekteydi (Koonce, 1984).

I. Dünya Savaşı esnasında ilk hava araçlarının becerilerinin geliştirilmesine ve bunları kullanacak insanların seçimine ve eğitimlerine özellikle büyük bir önem verildi. Bununla birlikte, havacılık psikolojisi kavramı da bu süre zarfında ilk kez Almanya'da 1915 yılında ortaya atılmıştır. İlerleyen yıllarda, havacılık psikolojisi hava aracının bizzat kendisine (özellikle irtifanın etkileri, G-kuvveti, gürültü, sıcaklık ve pilot üzerine olan diğer çevresel baskılar) odaklanmıştır (Koonce, 1984). Psikolojik testler ise Amerika Birleşik Devletleri'nin Massachusetts eyaletinde Hava Kuvvetleri öğrencilerinin katılımıyla Teknoloji Enstitüsünde yapılan araştırmalarla, haziran 1917 tarihinde başlamıştır. Bu testlerin sonucunda uçuş eğitim performanslarının, duygusal kararlılık, eğim algısı ve zihinsel atiklik arasında ilişkisi bulunmuştur; fakat burada kullanılan duygusal kararlı1ık, bugün kullandığımız duygusal kararlılıktan farklıdır (Koonce, 1984).

1920 ve sonrasındaki savaş yıllarında, İtalya, Fransa, İngiltere ve Amerika Birleşik Devletleri'nde havacılık psikolojisi yeniden gözden geçirilmiş ve 1939'da Amerika Birleşik Devletleri'nde Havacılık Psikolojisi Ulusal Araştırma Konseyi (NRC) kurulmuştur. 1947'de Amerikan Hava Kuvvetleri, havacilık psikolojisi hakkında Mavi Kitap da denilen 19 ciltlik bir seri hazırlamış ve 1949 yılında Amerika Birleşik Devletleri'nin Ohio eyaletinde havacılık psikolojisi laboratuvarı açılmıştır. 1956'da, Avrupa'da havacılık psikologları için Batı Avrupa Birliği (WEAAP) kurulmuştur. 1971'de Illinois Üniversitesi'nde daha gelişmiş bir 
havacı1ık araştırma laboratuvarı açılmış ve 1980 yılında da tüm bu araştırmalar kitap haline getirilmiştir (Koonce, 1984).

1980'li yıllardan sonra özellikle meteorolojik olayların havacılık psikoloji üzerine etkilerinin çalışılmaya başlanması daha da artmıştır. Uluslararası Sivil Havacılık Örgütü'nün (ICAO) belirli aralıklarla yaptıkları toplantılar ile yayınladıkları Annex 1-19 maddelik havacılık kurallarında sürekli geliştirmeler yapılmaktadır. Annex 3, sadece yağmur, sis, kar, alçak bulut yüksekliği vs. gibi meteorolojik etkilerin havacılık faaliyetleri ve havacılık psikolojileri üzerine olan etkilerinin araştırılmasını ve sonuçlarını içermektedir. Bununla birlikte, bu süre içerisinde jeomanyetik firtınaların etkileri henüz daha etkin bir şekilde ele alınmamıştı. Yaklaşık 200 yıldır bilinen jeomanyetik fırtınaların, askerî ve sivil havacılık üzerine etkileri 2013 yılında Birleşik Krallık Havacılık Sanayisinin yayınladığı belge ile ortaya konmuştur (Cannon et al., 2013a,b). Bu tarihten sonra jeomanyetik firtınaların havacılık psikoloji üzerine olan araştırmalarında ilerleme sağlanmıştır.

Farklı şiddetlerde görülen jeomanyetik firtınalar insan beyin aktivitesini ve fonksiyonlarını çok önemli derecede etkilemektedir. İnsan beyni, beyin zarı ile örtülü, farklı işlevlerden sorumlu sol ve sağ yarı küre şeklinde kafatasının içinde yer alan bir organdır. Sol yarı küre, sözel bilginin işlenmesi, bilgiyi parça parça ve sırayla işleyen, dikkatin odaklanması ve sürdürülmesinde önemli olan bölüm iken; sağ yarı küre, görsel algıda güçlü olan, bilgiyi parça parça değil, bütün olarak alan ve işleyen, dikkatin bir noktadan diğerine kaydırılmasını sağlayan, aynı anda paralel olarak birçok bilgiyi değerlendirebilen bölümdür (Ersoy ve Karal, 2012). Beynin her iki yarı küresi birbirini tamamlayan fonksiyonlara sahiptir. Bundan dolayı, beynin iki yarı küresi yaklaşık 250 milyon sinir lifinden oluşan sinirsel bir bağ aracılığılla bağ kurmakta ve herhangi bir öğrenmeye iki yarı küre de katkıda bulunmaktadır (Ersoy ve Karal, 2012).

İnsanların algılama, düşünme ve öğrenme yöntemleri arasında önemli farklar vardır. Bunun sebebi her kişinin beyin yapısının farklı bir algılama ve öğrenme sisteminde yaratılmış olmasıdır. Sinir (nöron) hücreleri ve glial (glue) hücreler olmak üzere iki tür hücrenin bulunduğu insan beyninin işlev görmesi, hücreler arasındaki iletişim ile gerçekleşir. Sinir sistemi ve beyin fonksiyonlarının ana öğeleri olan nöronlar, hücre gövdesi, dentrit ve akson olmak üzere 3 kısımdan 
oluşur. Dentritler hücreye gelen girişleri toplar ve hücre gövdesinde birleştirilerek bir çıkış darbesi üretilip üretilemeyeceğine karar verilir. Eğer bir iş yapılacaksa üretilen çıkış darbesi aksonlar tarafından taşınarak diğer nöronlarla olan bağlantılara iletilir. Nöronlar arasındaki bağlantılar hücre gövdesinde veya "sinaps" adı verilen dentritlerdeki geçişlerde olur. Beyinde bilginin öğrenilmesi ve saklanması sinir hücreleri arasındaki elektriksel ve kimyasal sinyallerle oluşur. Nöronlar hücrenin içinde ve dışında dağılmış bulunan sodyum, potasyum, kalsiyum ve klor gibi iyonlar vasıtasıyla, elektrik sinyallerini hücre duvarındaki voltaj1 değiş̧irerek üretirler. Bir hücre diğer bir hücreye elektrik enerjisini bu kimyasal iyonlar vasitasiyla transfer eder. Bazı iyonlar elektrik ve manyetik kutuplaşmaya sebep olurken bazıları kutuplaşmadan kurtulup hücre zarını açarak iyonların hücre gövdesine geçmesini sağlar. Sinyaller hücrenin etkinliğini (dürtüsünü) belirler. Bir nöron sahip olduğu dürtü miktarınca diğer hücreleri etkiler. Bazı hücreler diğerlerinin dürtülerini pozitif yönde, bazı hücreler de negatif yönde etkiler. Beyin ve sinir sistemi ile bilişsel davranışların oluşumu beyin temelli öğrenmenin temelidir. Beyin temelli öğrenme insan beyninin işlev ve yapısına dayanan, nörobilim, nörodilbilim ve bilişsel psikoloji ile bağlantı kuran bir öğrenme yaklaşımıdır (Ersoy ve Karal, 2012).

Yukarıda anlatıldığı gibi beynin farklı uzaysal ve anatomik bölüm fonksiyonları bulunmaktadır. Bizim bu makalede amacımı, jeomanyetik firtınaların bu beyin fonksiyonları üzerinde ne tür bir değişime sebep olacağının araştırılmasıdır. Babayev ve Allahverdiyeva (2005) makalesinde, elektroensefalogram (EEG) inceleme sonuçlarının, insan beyninin fonksiyonel durumunu yansıtan en objektif yöntem olduğunu belirtmişlerdir. Güçlü manyetik firtınaların olduğu dönemlerinde, hastaların çoğunluğu için uyumsuzluk, zayıflık ve farklı bölgelerde baş ağrılarının varlığı kaydedilmiştir. EEG üzerindeki tanımlanmamış kaymaların karmaşıklığının, muhtemelen artan senkronizasyon dengesizliği ile birlikte serebral korteksin altındaki bütünleştirici sistemlerde görülen işlev kaybı ile bağlantılı olarak, jeomanyetik firtınalardan etkilenen insan beyninin yarı kürelerinin korteksindeki düzensiz fonksiyonel aktiviteyi yansıttığını göstermişlerdir. Yine aynı makalede, insan beyninin kasılmalardan sorumlu olan mekanizmasının eşik değerinin azaldığı belirtilmiştir. Genel olarak, zayıf ve orta seviyeli jeomanyetik fırtınaların uyarıcı bir etki gösterirken; çok şiddetli 
firtınalarda belli bir süre kuvvetli bir etki olduğu fakat sonrasında aynı nöronların çalışma presibinde olduğu gibi bir yerden sonra artık uyarı olmayıp, sistemin bloklanacağı sonucuna varmışlardır.

Öz kısmında da bahsedilen, sebebi belli olmayan baş ağrıları, hareket fonksiyonlarında düzensizlik, denge bozukluğu gibi organik problemlerin havacılıktaki en önemli nedenleri havacılık tıbbının ana konuları olan hipoksi (yüksek irtifalara çıkma, hipoventilasyon ya da kanın normal gaz seviyesini korumak için gerekli olan hava giriş çıkışının normalin altında gerçekleşmesi, solunum yolu hastalıkları gibi nedenlere bağlı olarak akciğer aracılığıyla atmosferden kana oksijen geçişinin azalmasi), akselerasyon kuvvetleri (cismin yer çekimine bağlı olarak hızında ve/veya istikametinde meydana gelen değişiklik), uzaysal dizoryantasyon ya da uçucu vertigosu (vücudun denge sistemlerinden yani beyinciğe bildirim gönderen gözlere, iç kulaklara ve boyun ve omiriliğe yanlış uyarılar gelmesi veya doğru uyarıların yanlış algılanmasıyla ortaya çıkan dengesizlik hali), yorgunluk, shift-lag (coğrafi bölge değişiklikleri, yoğun çalışma zamanları, uyuma periyodunun kısmen veya tamamen yer değiştirmesi hallerinde vücudun iç ritminin bu yeni düzene uyamamasından kaynaklanan zorlanma durumu), jet-lag (boylamlar geçilerek yapılan uzun menzilli ve yüksek hızlı kıtalararası yolculukların ve içsel-biyolojik saat ile varılan bölgenin coğrafi saati arasındaki uyumsuzluğun sebep olduğu bir dizi zihinsel ve fiziksel performans bozuklukları), termal stres (sıcaklığın artması sonucu oluşan ve rahatsızlık veren durum) ve dehidratasyon ya da su kaybı gibi konulardır. Bu durum, jeomanyetik firtınaların etkisine çok daha büyük oranda maruz kalan pilotlarda çok daha etkili olacaktır. Babayev ve Allahverdiyeva (2005), insan beyninin fonksiyonel durumlarının jeomanyetik firtınalara göre değişimini görüntülemek için EEG araştırması yapmışlardır. Biz de Babayev ve Allahverdiyeva (2005) araştırmalarından elde edilen sonuçlar ile ülkemizde bu konuda ilerleme yolunda yapılması gereken işlemlerin neler olduğunu konusunu tartışacağız. $\mathrm{Bu}$ tartışmalardan yola çıkarak, konu ile ilgili araştırma yapmak isteyen psikolog, hekim, biyolog ve diğer araştırmacıların çalışmaları için ihtiyaçları olan konuya ilişkin astronomi ve fizik bilgileri de makalemiz dâhilinde sunulacaktır. 


\section{Jeomanyetik Fırtınaların İnsan Beyninde Etkilediği Bölgelerin Tanımlaması}

Jeomanyetik fırtına, belli dönemlerde dünya manyetosferinin (Yüklü parçacıkları tuzaklayıp, yönlerini değiştirecek şekilde dünya ve diğer gezegenlerin etrafını kuşatan kuyrukluyıldız benzeri bir yapıdır. Güneş rüzgârı ve gezegenlerin manyetik alanları manyetosferin şeklini belirler) düzenini bozucu etkiye sahip bir astronomik olaydır (Timoçin, Ünal, Tulunay ve Göker, 2018a; Timoçin, Ünal ve Göker, 2018b) ve fiziksel birimi nanoTesla [nT] ile ifade edilir. Bir jeomanyetik fırtınaya sebep olan güneş kaynaklı etkiler, koronal kütle atılımları (Güneş rüzgârının âni olarak artmasına neden olan patlamalardır), koronal delikler (Güneş'in X-1şınlarında gözlenmesi sırasında geniş kara delikler halinde görülen, aylar hatta yıllarca sürebilen değişken güneş olaylarıdır), güneş parlamaları (flare) olup, bu etkileri dünyaya doğru ileten ise şok dalgaları yoluyla ilerleyen güneş rüzgârlarıdır (Göker, 2008; Göker, 2012; Göker, 2017a; Göker, 2017b; Göker, 2018). Güneş rüzgârları, dünyanın manyetosferiyle etkileşime geçtiği andan yani olay anından- itibaren, 24-36 saat sonrasında bile etkisine devam eder. Jeomanyetik fırtınanın Dünya manyetosferi ile etkileşme zamanı ve jeomanyetik firtınanın şiddeti, firtına bozucu zamanı (Dst) denen bir parametre ile ölçülür ve birimi $[\mathrm{nT}]$ 'dir.

$D s t^{*}=D s t-b \times P_{S W}^{0.5}+c$

Burada, Dst ${ }^{*}$ indeksi, manyetopoz (magnetopause) akım etkilerinin (Dünya'nın manyetik alanının güneş sistemi arasındaki sınırını belirleyen manyetopozdaki plazma akımları) düzeltilmesine karşılık gelen basınç düzeltmesi yapılmış Dst indeksi olarak tanımlanır; Dst indeksi, manyetosferin kuyrukluyıldız benzeri bir yapı olmasından dolayı manyetopoz akımında ve kuyruk akımlarındaki jeomanyetik alan değişimlerinin bileşenlerini içermektedir; $b$ ve $c$ değerleri analiz sonucu elde edilen sabitlerdir ve $P_{S W}$ güneş rüzgarı dinamik basıncıdır (Dinamik basınç, akışkanın hareketi yönünde oluşan basınçtır) ve [nPa] ile ölçülür (1 nanoPascal $=10^{-15}$ Newton $/ \mathrm{mm}^{2}$ ) (Burton, McPherron ve Russell, 1975). Genel olarak kullanılan $b$ ve $c$ değerleri sirasıyla $b=7,26\left[\mathrm{nT}(\mathrm{nPa})^{-1 / 2}\right]$ ve $c=11[\mathrm{nT}]$ olmaktadır (O’Brien ve McPherron, 2000).

Jeomanyetik firtınaların şiddetini ölçen diğer bir parametre ise $K$-index (ya da gezegensel $K_{p}$-index) adını alır. Bu parametre, dünya manyetosferinin sakin 
(hiçbir etki altında olmadığı) durumundan, jeomanyetik firtına olduğu ana kadarki değişimleri yakalamak için her 3 saatte bir gözlem verisi almaktadır ve 0 (en sakin) ile 9 (en bozucu) arasında aldığı değerler ile firtınanın şiddeti ölçülebilir (http://www.ises-spaceweather.org/). Uydu teknolojisinin gelişimiyle birlikte, dünya manyetosferinin yapısı daha detaylı bir şekilde araştırılmaya başlanmıştır. $\mathrm{Bu}$ araştırmalar neticesinde elde edilen en önemli sonuç, güneşten çıkan ve güneş rüzgârları yoluyla dünyamıza taşınan kütle, momentum ve enerji gibi yüksek rasyasyon kaynaklarının, daha sik olarak yüksek enlemlerde meydana gelen manyetosfer-iyonosfer-termosfer sisteminde görüleceği yönündedir. Fakat bu kozmik radyasyonun (yani jeomanyetik firtınanın) şiddeti çok büyükse nadirde olsa orta enlemlere kadar indiği de ölçülmüştür.

Jeomanyetik aktivitenin artması, dünya manyetik alanının yatay bileşenindeki azalmaya bağlı olarak sürüklenme hızında meydana gelecek azalmaya ve manyetik enlemlerin artışıla birlikte iyonosferdeki elektron yoğunluğundaki azalmaya bağlıdır. Bununla birlikte, güneşin 11 ylllık aktivite çevrimi ve 22 yıllık manyetik çevrimi de jeomanyetik firtınaların şiddetinde önemli değişikliklere sebep olacaktır. Bu nedenle, güneş aktivite çevrimine göre iyonosferiç manyetosferde meydana gelen firtınalar ve manyetosferik firtınaların ölçümleri için bir denklem oluşturulmuştur. Artan firtına sayılarının genel değişimi aşağıda verildiği gibidir (Gulyaeva ve Stanislawska, 2008):

$$
Y=a+b \Phi
$$

Burada, $Y$ değeri $W_{p}$ (Dalga ve gezegensel etkilere bağlı, düşük enlemler için yer teleskoplarıyla gözlemi yapılabilen bir indekstir), $D s t$ ve $A_{p}$ (Jeomanyetik aktivitenin günlük ortalama değerini verir) indislerine ait bir sabittir ve $a$ ile $b$ katsayılarına göre değişir; $a$ ve $b$ katsayıları güneş aktivite çevrimine göre firtına sayısına ait sabitlerdir; $\Phi$ ise güneş çevriminin evresini vermektedir.

$$
\Phi=(T-m) /(M-m)
$$

olarak verilir. Burada, $T$ firtınanın olduğu ayı, $m$ güneş minimumunun olduğu ayı ve $M$ güneş maksimumunun olduğu ayı göstermektedir. 1999 yılından bugüne kadar bahsi geçen $\Phi$ değeri " 0,1 " " olarak bulunmuştur (Gulyaeva ve Stanislawska, 2008).

Jeomanyetik firtınalarından dolayı artan radyasyon miktarı, pilot ve diğer uçuş ekibi üzerinde önemli bir negatif etkiye sahip olacaktır. Özellikle, yüksek 
enlemlerde ve kutup bölgelerinde gerçekleştirilen uçuşlarda kozmik radyasyonun etkisi çok daha yoğun hissedilecektir. 20 yılı aşkın süredir yapılan kaza raporları istatistiklerinden, uçak kazalarının \%70-80'inin insan faktörü kaynaklı olduğu bilinmesine rağmen, meteorolojik olaylardan kaynaklanan kazalar bu sayının \%2030'unu oluşturmaktadır (National Trasportation Safety Board, 2005). Amerika Birleşik Devletleri'nde kurulan Ulusal Taşıma Güvenlik Kurulu (NTSB) 1968, 1974 ve 1989 tarihinde görülen hava ve görüş sahası kaynaklı uçak kazalarını raporlamışlardır, kaldı ki bu raporlar ve daha sonraki yıllarda hava koşullarına bağlı olarak yapılan uçak kaza raporları sadece yağmur, sis, alçak bulut yüksekliği ve kar denilen meteorolojik kaynaklı olaylardır (National Transportation Safety Board, 2005). Henüz bu tarihlerde jeomanyetik firtınaların uçuş araçlarına zarar verici etkileri daha bilinmemekteydi. Jeomanyetik firtınalar, fiziken iyonlaşmış radyasyon alanları olarak tanımlanır. Atmosferik iyonlaşmaya iki kaynak sebep olur: (1) Güneş sisteminin dışında sürekli var olan geri zemin galaktik kozmik 1şınlar; (2) Birkaç saatten birkaç güne kadar değişen zaman aralığına sahip, güneş yüzeyindeki patlamalardan dünyaya doğru gelen yüklü enerjik parçacıklardır (Mertens, Kress ve Wiltberger, 2010). İlk bahsi geçen kaynak daha çok astronotları etkilerken, ikinci kaynak dünyada hareket eden hava araçlarını etkilemektedir. Son güneş çevriminde (23. Güneş çevrimi), ekim ve kasım 2003 tarihleri arasında görülen ve Hallowen adı verilen çok şiddetli jeomanyetik fırtına buna en güzel örnektir (Mertens, Kress ve Wiltberger, 2010).

Çok şiddetli jeomanyetik firtınalarda, halsizlik, keyifsizlik ve sebebi belli olmayan bölgesel baş ağrıları en belirgin rahatsızlıklar olup, bütünleyici korteks altı sistemlerindeki işlev bozukluğu ve artan denge bozukluğu ile bağlantılı olan beyin korteksinin hareket fonksiyonlarında da düzensizliğe neden olur (Babayev ve Allahverdiyeva, 2005). Bahsi geçen makalede (Babayev ve Allahverdiyeva, 2005), sadece yerde bulunan insanlar üzerinde yapılan deneylerde, jeomanyetik aktivitenin şiddetli olduğu günlerde sağ korteks küresinin belirli zaman aralıklarında âni ve kısa süreli döngülere sahipken, jeomanyetik olarak sakin günlerde beynin iç bölgesi ve iç küresinin zayıf bir şekilde etkilendiği görülmüştür. $\mathrm{Bu}$ çok önemli bir bulgudur; fakat hava araçlarının içindeki pilotlar üzerine jeomanyetik firtına etkilerinin nasıl olacağı, yerdeki deneklerde bu kadar şiddetli etki gösteren jeomanyetik firtınanın yaklaşık dünya troposferine yakın 
yükseliklerde uçan uçuş ekibi ve yolcular üzerine hangi düzeyde bir negatif etki yapacağı temel hatlarıyla çok sayıda makalede ele alınmış olmasına rağmen, jeomanyetik firtına şiddetleri (şiddet ölçümleri yukarıda verilen denklemler ile yapılmaktadır) ile uçuş ekibi ve yolcular üzerine bu şiddetler doğrultusunda yapılan etkiler henüz daha ele alınmamış bir araştırmadır.

$\mathrm{Bu}$ fırtınaların en büyük etkisinin korteks üzerinden doğrudan sinir sistemi üzerine olması beklenmektedir. Korteks üzerinden doğrudan sinir sistemi üzerine olacak bir etkinin sonucunda, davranışlarda saldırganlık, farklı nöbet durumları, sinir sistemine bağlı ruhsal bozukluklar ve intihar girişimleri çok sık görülmekle birlikte, nöropsikolojik hastalıklar da artmaktadır (Cüceloğlu, 1999). Bununla birlikte, Babayev ve Allahverdiyeva (2005) makalesinde, kan viskozitelerinin fırtına zamanlarında belirgin bir şekilde arttığı, hatta bazı durumlarda ikili pik şeklinde de artışın olduğu ve kırmızı kan hücrelerinin yapışkan hâle gelerek, kan akışının yavaşladığı belirtilmiştir.

Peki, bu beyin korteksi ve sinir sistemi etkileşimi nasıl olmaktadır? Gözde, kulakta, deride ve diğer duyu organlarındaki fiziksel enerjiyi sinirsel enerjiye çeviren görütücü (efferent) gruplar adı da verilen hücre gövdeleri, oluşan bu enerjiyi beyine iletip dış dünyayı algılamamızı sağlar. İletilen bu enerjiden, beyin ve omurilik mesajlar üreterek, bu mesajları getirici (afferent) gruplar ile tepki ouşturacak şekilde kaslara ve iç salgı bezlerine taşır. Tüm bu etki-tepki işlemlerini derleyen, toplayan, birleştiren ve koordine eden esas iç nöronlardır ve bunlar birleştirici (connecting) gruplar olarak adlandırlırlar (Cüceloğlu, 1999). Tepkinin tamamı bir saniyeden çok daha kısa bir sürede ortaya çıkmaktadır, böylesine yüksek bir hız ise bilginin sinir sisteminde çok hızlı iletilmesiyle olanaklıdır (Gegenfurthner, 2005). Uyarıcının şiddeti arttıkça, nöronun uyarılma frekansı artar ve uyarıcının şiddeti daha kuvvetli bir biçimde hissedilir. Uyarıcı şiddeti çok yüksek olduğunda ise bir yerden sonra artık uyarılamaz.

Beyin kabuğunda özellikle jeomanyetik firtınalardan etkilenme sürecinde görme, işitme ve beden duyularında önemli bir değişim olacağı düşünülmektedir. Çünkü bedenin daha hassas davranışlar yapması ve kas koordinasyonunu gerektiren kısımları motor korteksin değişik bölgelerinin elektrikle uyarılması yoluyla bedenin o bölgelerine karşılık gelen kısımların harekete geçmesiyle mümkündür (Cüceloğlu, 1999; Carlson, 2014). Temporal korteksin zarar 
görmesiyle oluşan lezyonlar, farklı algısal uyarıcılar arasındaki ayrımları fark edebilme becerisini zarara uğratır ve kısmî görsel bilgi türlerini algılama becerisini azaltır (Carlson, 2014).

Jeomanyetik fırtınaların beyin korteksi üzerine etkisini yukarı da anlatmıştık. $\mathrm{Bu}$ etkiye bağlı olarak, beyin lobları da etkilenecektir. Babayev ve Allahverdiyeva (2005) makalesinde de belirtildiği gibi firtınanın en etkilediği beyin lobu sağ yarım küresidir. Peki, beyin loblarının işlevleri nelerdir? Beyin yarım kürelerinin vücutla çaprazlama bir ilişkisi vardır: Sol beyin yarım küresi, vücudun sağ yarısından gelen duyuları alıp sağ tarafını hareket ettirirken; sağ yarım küre de, vücudun sol yarısından gelen duyuları alıp sol tarafını hareket ettirir. İki yarım küre arasındaki fark, sağ yarım kürenin daha çok görsel-mekânsal-uzaysal materyalin işlenmesini gerektiren bilişsel işlevlerde daha üstünken; sol yarım küre sözel beceriler konusunda üstündür, sol beyin yarım küresinde parietal, temporal ve frontal loblarda bazı bölgeleri içeren, dil işlevleriyle ilişkili alanlar ve yapılar bulunur (Öktem, 2013).

\section{Jeomanyetik Fırtınaların İnsan Beyin Fonksiyonları Üzerine Etkilerinin Tartışılması}

Önceki bölümlerde, ilk olarak havacılık psikolojisinin kısa bir tarihçesi verilerek, nörofizyolojinin pilotların bilişsel ve kişilik psikolojilerinin araştırılmasında ne kadar önemli olduğu belirtilmiştir. İkinci bölümde, jeomanyetik firtınaların ne tür bir yapı olduğu kısaca anlatılmış ve bu firtınaların insan beyninde hangi bölgeleri etkilediğine değinilmiştir. Bu bölümde ise bu firtınaların belirtilen beyin bölgelerine nasıl bir etki yapacağını tartışacağız.

Bir pilotun, çevresel etkilerin çok baskın olduğu bir durumda uçabilmesi için berrak bir zihin, güçlü bir kas koordinasyonu, algılama, bellek, bilgi işleme gibi bilişsel davranışlara hâkimiyet yeteneği ve cesaret, özgüven, öfke kontrolü sağlam, risk durumlarınla başa çıkabilecek kişilik özelliklerine sahip olması gerekmektedir. Bahsi geçen bu durumlar ister askerî pilot, ister sivil hava taşımacılığı pilotu olsun, her iki grubun da sahip olması gereken özelliklerdendir; fakat yağmur, kar, sis, alçak bulut yüksekliği gibi temel meteorolojik sebepler uçuşlarda pilotların işini hayli zorlaştırmaktadır. Buna ilâveten, çok daha tehlikeli bir durum ise pilotun 
yüksek radyasyona maruz kalmasıdır. Uçuş personeli radyasyon çalışanı kategorisindedir ve radyasyon limiti $20 \mathrm{mSv}$ (milisievert)/yıldır. Bu değer halk için $1 \mathrm{mSv} / y ı l d ı r$. Yılda 600 saat uçuş yapan bir uçuş personelinin maruz kalacă̆l limit 1,5 mSv'dir (http://www.icrp.org/icrpaedia/limits.asp). Bununla birlikte, yüksek enlemlerde olan ve 1000 saat civarında uçuş yapan bir uçuş personeli için bu risk çok daha yüksektir. Bizim gibi yüksek enlemlerde olmayan ülkelerin uçuş personeli için risk daha düşüktür. Yapılan çalışmalarda 20 yıl içerisinde yıllık 5 mSv'lik maruz kalma durumu kanser riskinde \%0,1-0,4 artışa neden olmakta, bu maruz kalma süresi 30 yıl olduğunda oran 0,6 'ya çıkmaktadır. İnsanın maruz kaldığı radyasyonun \%50'si doğadaki radondan gelir. Sadece \%10’u kozmik radyasyondan gelmektedir. İyonizan radyasyonun (radona bağl1) zararlı etkileri bir zamanlar tanı ve tedavi amacıyla kullanılan yüksek enerjili X-ışınları ile radyum ve diğer doğal radyasyon kaynakları ile sınırlı idi. Bugün ise başlıca radyasyon kaynakları, nükleer reaktörler, siklotronlar, lineer akselatörler, kanser tedavisinde kullanılan ruhsatlı kobalit ve sezyum kaynakları ile tıp ve endüstride kullanılan sayısız yapay radyoaktif maddelerdir (Berkow et al., 1992). Radyasyonun alınış hızı (doz hızı), radyasyon dozu/birim zaman olarak ifade edilir. Yerkürede doğal olarak bulunan en düşük radyasyon dozunda (1-2 $\mathrm{mSv} / \mathrm{yll}$ ) hiçbir etki görülmez iken, ölçülebilir etki görülme olasıllı̆ı doz hızı ile toplam doza paralel olarak artar. Tek ve yüksek bir $m S v$ dozunda belirgin bir etki gözlenir iken, aralıklı olarak düşük dozda alınan radyasyonun etki göstermesi için çok yüksek dozlara ulaşması gerekmektedir. Yüksek dozlar ani somatik etkilere neden olurken, düşük dozların geç somatik etki ile uzun vadede genetik etki yapma olasılığı vardır. Radyasyona maruz kalan vücut alanı da önemlidir. İnsan vücudunun tamamının ölüm olmaksızın alabileceği toplam doz yaklaşık $2 \times 10^{3} \mathrm{mSv}$ 'dir. Toplam doz $4.5 \times 10^{3}$ $m S v$ 'e ulaştığında ölüm olasılığı \%50 kadardır. Vücudun aldığı toplam doz çok kısa bir sürede $6 \times 10^{3} \mathrm{mSv}$ üzerine çıkar ise öldürücü olur (Berkow et al., 1992). Şiddetli bir jeomanyetik firtınada bu radyasyon etkisinden kaçmak neredeyse imkânsız denilebilir. Yukarıda bahsi geçen beyin bölgelerinin böyle bir radyasyona maruz kaldığında nasıl etkilendiğini aşağıda tartışacağız:

1. Çok şiddetli jeomanyetik firtınalarda, halsizlik, keyifsizlik ve sebebi belli olmayan bölgesel baş ağrıları en sık görülen durumdur. 
2. Beyin korteksinin etkilenmesiyle, hareket fonksiyonlarında düzensizlik ve denge bozukluğu başlayacaktır.

Jeomanyetik firtınalar, 1. ve 2. maddelerinde belirtilen organik problemlerin sebeplerinden biri olmakla birlikte, bu problemlere neden olan en önemli ve başlica etkiler hipoksi, akselerasyon kuvvetleri, uzaysal dizoryantasyon, yorgunluk, shift-lag, jet-lag, termal stres ve dehidratasyon olarak gösterilir. Hipoksi durumunda, 3500-4000 metre irtifadan sonra volonter hareketler güçleşir (kas koordinasyon yetersizliği). Kramp ve kontraksiyona meyil uyanır, refleks yavaşlar. Zekâ faaliyeti (dikkat, hafiza, muhakeme) azalır. Fizik-psişik kronik yorgunluk başlar, düşünen irade zayıflar. Bilişsel olarak baş ağrısı, depresyon, dalgınlık, hatalı kararlar ve uyku hali görülürken, psikolojik olarak içgörü azalması, özgüven artışı, gereksiz risk alma, umursamazlık, inatçılık ve agresif tepkiler baş gösterir. Görsel olarak bulanık görme, gece görüşü azalması ve renk ayrımında zorlanma baş gösterir iken, fiziksel olarak nefes darlı̆̆ı, hiperventilasyon (aşırı nefes alma), baş ağrısı, baş dönmesi, bulantı, paresteziler, taşikardi ve yorgunluk görülecektir. İdrakte yetersizliğe meyil, hareketlerde uyum ve sinerjinin düzensizliği, itimatta artma (öfori) olur ki buna "irtifa sarhoşluğu" denir (Çetingüç, 2016).

Akselerasyon durumunda ise, fizik kondüsyonu yetersiz veya anti-G manevralarını usulünce yapamayan pilotlarda görme alanı kararması, bilinç kaybı ve konvulsif senkop ortaya çıkabilir. Jet uçaklarında, kanın beyinden aşağı dokulara çekilmesi yani beyin seviyesinde kan basıncı azalması, beyin hipoksisi sonucu ortaya çıkan bu durumlarda pilot en az 15-30 sn. uçağa kumanda edemez. Buna ek olarak, şaşkınlık, konfüzyon, farkındalık kaybı, öfozi, amnezi ve karar verme zorluğu gibi bilişsel bozukluklar görülecektir (Çetingüç, 2016).

İnsanın uzaydaki oryantasyonu 4 sistemin (görsel, işitsel, vetibüle ve proprioseptif) koordinasyonu ile sağlanır. Denge ve pozisyon algısında görsel algının payı $\% 79$, derin duyunun $\% 5$, vestibülünkü $\% 15$ ve işitsel sistemin payı $\% 1$ 'dir. Dizoryante pilot sadece bir pozisyon algı hatası içinde değil; aynı zamanda uçuş aletlerini doğru okuyup yorumlama ve doğru kararlar verme konusunda da bilişsel zafiyetler gösterir; tepki süresi uzar, zihinsel şaşkınlık içine girer, inkapasite olur. Bu durum, uzaysal dizoryantasyon olarak adlandırılır (Çetingüç, 2016). Jet-lag durumunda, somatik, bilişsel ve psikolojik bozukluklar ortaya çıkar. Somatik olarak iştahsızlık veya uygunsuz zamanlarda açlık hissi, yorgunluk, 
bağırsak tembelliği (kabızlık), uykusuzluk veya ani uyku basması görülür. Bilişsel olarak da dikkat, konsantrasyon, yargi-bellek kusurlar1, zaman ve mesafe algisı bozulması, tepki zamanı uzaması, anlama ve öğrenme işlevlerinde gecikme olur. Psikolojik sorunlar arasında öne çıkanlar, anksiyete, iritabilite, sinirlilik, depresyon ve bazen öforidir. Shift-lag durumunda, alışkın olunan çalışma-dinlenme periyodunun değiştirilmesiyle, vücut 1sısı, kan şeker düzeyi ve zihinsel çalışma kapasitesi etkilenir. Bu durumda, yorgunluk, uykusuzluk, sindirim sistemi ve diğer somatik yakınmalar ile genel keyifsizlik hali görülür (Çetingüç, 2016).

3. Gelen radyasyonun eğer sadece sağ beyin korteksinde önemli bir etkiye sahip olması söz konusu ise, sağ yarım kürenin görsel-mekânsal-uzaysal materyal gibi bilişsel işlevlerden sorumlu olduğunu düşündüğümüzde, zaten uçmanın esas kuralı olan görsel, mekânsal ve uzaysal hesaplama kabiliyeti etkilenmiş olacaktır. Pilot bu durumda, önemli hesapları unutabilir, yanlış hesaplamalar yapabilir ve olayları dikkatlice değerlendirme yetisini yitirebilir. Burada pilotun bilişsel ve kişilik özellikleri yeterince gelişmişse bu etkiyi en aza indirgeyebilme yetisine sahip olacaktır. İndirgeyemediği taktirde, yani korkularının üstesinden gelecek duygusal düzenleme kapasitesine sahip değilse, duraksayabilir, paniğe kapılabilir ve görevini yerine getiremeyebilir. Büyük sinirsel gerginlik pilotun zaman duyusunu da çarpıtabilir. Psikolojik olarak korku, ürküntü, panik adını verdiğimiz şeylerin fizyolojik temelinde, beyin yarıkürelerinin kısıtlayıcı durumu vardır. $\mathrm{Bu}$ durum çeşitli edilgen-savunmacı refleks düzeylerine denk düşer (Gagarin ve Lebedev, 1984).

4. Beyine bilgi getiren sinir sistemi etkilendiğinde ise (Cüceloğlu, 1999);

a. Kalpte enfarktüs, nöbet durumlarl, sinir sistemine bağll ruhsal bozukluklar görülürken, radyasyonun etki süresi uzadıkça bu bozukluklar daha da rahatsiz edici duruma gelecektir.

b. Bu gibi acil ve âni karar verilmesi gerektiren durumlarda, kan basıncının ve kalp atışının artmasına, solunum sayısının artmasına, gözbebeğinin genişlemesine, terlemenin artmasına, tükürük salgılamasının azalmasına, kandaki şeker miktarının artarak daha fazla enerjinin ortaya çıkmasına, kanda pıhtılaşma faktörlerinin artmasına, kanın sindirim organlarından beyne ve çizgili kaslara yönelmesine neden olacaktır. 
5. Beyin kabuğunda özellikle jeomanyetik firtınalardan etkilenme sürecinde görme, işitme ve beden duyularında değişim önemli olacaktır. Bu gibi durumlarda bedenin daha hassas davranışlar yapması ve ayrintıl kas koordinasyonu gerektiren kısımlarda motor korteks etkili olacaktır.

6. Temporal korteksin zarar görmesi durumunda oluşacak lezyonlar, farkl algisal uyarıcılar arasındaki ayrımları fark etme becerisini zarara uğratacak ve kısmî görsel bilgi türlerini algilama becerisini azaltacaktır.

Maddeler halinde siraladığımız, tüm bu etkilenen bölgeler üzerine teker teker, dikkatlice ve detaylı olarak en başından testler yapılması gerekmektedir. Belki de bu belirlenen bölgeler haricinde, farklı duyu bölgelerinde de başka tür sonuçlarla karşılaşılabilir. $\mathrm{Bu}$ araştırma uzun soluklu bir araştırma olma potansiyelindedir.

\section{Sonuçlar ve Gelecekte Yapılabilecek Çalışmalar}

Jeomanyetik fırtınaların, askerî ve sivil havacılık psikolojisi üzerine etkilerine ilişkin çalışmalar 2013 yılında esasen Birleşik Krallık'ta hız kazanmaya başlamıştır; fakat Türkiye'de henüz daha meteorolojik ve astronomik nedenlerden kaynaklanan uçak kazaları raporlarına bakılmamış olup, henüz daha bir araştırma laboratuvarı kurulup denekler üzerinde bu etkiler araştırılmamıştır. Ayrıca Türkiye orta enlemlerde bulunan bir ülke olduğu için yüksek enlemler ve kutup bölgelerindeki pilotların birebir yaşadığı jeomanyetik fırtına etkisine sahip olunamaz, bu nedenle laboratuvar çalışmalarının bir an evvel hız kazanması gerekmektedir. $\mathrm{Bu}$ nedenle, bu makalemin bu çalışmalara öncülük etmesini ummaktayım. Ülkemizde hava yolu pilotları radyasyonun etkileri konusunda oldukça endişe duymuşlar ve geçtiğimiz yıllarda bu konu ile ilgili uçak içi ölçümler yapılmış, hatta Sivil Havacılık Genel Müdürlüğü ve Türkiye Havayolu Pilotları Derneğinin ortak düzenlediği bir çalıştay yapılmıştır. Fakat, bu çalışmalar direkt olarak jeomanyetik fırtınaların etkilerini araştırmamışlardır. $\mathrm{Bu}$ nedenle, bu uygulama hayata geçtiği durumda Türkiye'de bu konuda ilk kez yapılacak olan bir deney niteliğinde olacaktır. Gelecekte ne tür çalışmalar yapılabilir:

1. Öncelikle jeomanyetik firtınanın tüm fiziksel parametrelerinin oluşturulacağı temel ve diğer bozucu etkilerden arındırılmış bir laboratuvar ortamı 
fen ve mühendislik sahalarının araştırmacılarıyla, klinisyenlerden gelecek bilim insanları ile kurulmalıdır. Bu ilk aşamada sadece jeomanyetik firtınanın etkisi belirlenecektir. Sonrasında çalışmanın daha kapsamlı hale getirilmesi için ilgili deney mutlaka gerçek uçuş şartlarını simüle eden alçak basınç odası, insan santrifüjü, iklimlendirme laboratuvarı gibi ortamlarla ayrıca gerçekleştirilmeli ve gerekli karşılaştırılmalar yapılmalıdır.

2. Hem askerî pilotlardan ve hem de sivil havacılık pilotlarından bilişsel psikoloji ve kişilik psikolojisinden aldıkları test sonuçlarına, farklı yaş ve fiziksel durumları vs. özelliklerine göre denekler seçilmelidir (İlk sınıflama).

3. Deneklerin kullandığı uçak tiplerine göre ayrı bir sınıflandırma daha yapılmalıdır (Ikinci siniflama).

4. Farklı jeomanyetik firtına şiddetlerine karşıllk gelen ortamlarda denekler teste tabi tutularak ve 0-9 arasında farklı şiddet değerlerine maruz

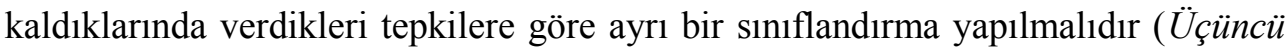
siniflandırma).

5. Birkaç saatten, birkaç güne kadar jeomanyetik firtınaların etkisinin sürmesi durumuna göre, etkiye maruz kaldıkları sürelere göre de ayrı bir sınıflama yapılmalıdır (Dördüncü sinıflama),

6. Her deney bitişinden hemen sonra, gerekli tıbbî ve psikolojik muayene ile pilotlar nörofizyolojik testerden geçirilmelidir. Böylece teste tâbi tutulmadan önce ve tutulduktan sonra pilotlarda görülen psikolojik ve fizyolojik değişimler gözlemlenebilecektir. $\mathrm{Bu}$ deneylere ek olarak; uçuşta o an için maruz kalınan hipoksi vs. gibi fizyolojik etkenlerin işin içine katılması da gerekmektedir.

Yüksek enlemlerde uçan pilot ve uçuş ekibi, jeomanyetik firtınanın etkisini birebir yaşayacaktır; hâlbuki Türkiye gibi orta enlemlerde hava taşıtı kullanan pilot ve uçuş ekibinin ancak laboratuvar ortamında test edilerek, bu etkilere verdikleri tepkiler ölçülebilir. Bahsi geçen bu deneylerin havacıllk psikolojisi literatüründe ilk kez uygulanacak olması nedeniyle de bu hipotez ayrı bir önem taşımaktadır.

Teşekkür: Bu makalenin hazırlanması esnasında yardımlarını esirgemeyen İstanbul Üniversitesi Edebiyat Fakültesi Psikoloji Bölümü ile Havacılık Psikolojisi Enstitüsü'nden Prof. Dr. Pınar ÜNSAL, İstanbul Medeniyet Üniversitesi Tıp Fakültesi İç Hastalıkları Anabilim Dalı'ndan Uzm. Dr. Uluğ Mutlu GÜNAYDIN, İDE Terapi Merkezi'nden Uzm. Psikolog Hanife UĞUR KURAL, İstanbul Gelişim 
Üniversitesi Sosyal Bilimler Enstitüsü Klinik Psikoloji Yüksek Lisans Öğrencisi Ruhicem YALABIK ve bu makalenin yazılmasına beni teşvik eden İstanbul Bilgi Üniversitesi Sosyal ve Beşeri Bilimler Fakültesi Müzik Bölümü Lisans Öğrencisi Halit Oğuz GÜNAYDIN'a teşekkürlerimi bir borç bilirim.

Bununla birlikte, makalemi okuyan Editör ve Hakem Kurulu'na da teşekkürlerimi iletmekteyim.

\section{Extended Summary}

This article describes the expected damages to the brain and nervous system caused by the effects of geomagnetic storms, based on the results of previous studies on geomagnetic storms and neurophysiological studies. The organic processes that occur in the brain are reflected in the behaviors which are exhibited after passing through the muscles. In the simplest term, environmental changes such as air pressure, heat, or humidity affect neurobiochemical events in the body, and our behaviors that appeared from these neurobiochemical changes can also be examined neurophysiologically.

The most common meaning of "Aviation Psychology" is that it is the application of the body of knowledge concerning humans' behavioral capabilities and limitations to the aviation industry, such as the performance of flight crew members, passengers, managers, and controllers in the air traffic control system, airport personnel, and those persons involved with the design, sale, and maintenance of aircraft. The first aviation psychology term was established in Germany in 1915. The evaluation of the psychological tests was begun on June 1917 at the Massachusetts Institute of Technology in the United States of America with attending Army Aviation Cadets. National Research Committee (NRC) on aviation psychology was first established in the United States of America in 1938 and afterward, these efforts have documented a series of 19 books in 1947 with the name of "Blue Books". In 1949, the first aviation psychology laboratory was opened in Ohio State in the United States of America. In 1956, the Western European Association for Aviation Psychologists (WEAAP) was started for the European aviation psychologists. A new aviation research laboratory was opened in Illinois University in the United States of America in 1971, and all previous 
studies about aviation psychology were documented in 1980. The 1980s, the study of the effects of meteorological phenomena on aviation psychology was increased. The Annex (Annex 3) of International Civil Aviation Council (ICAO) includes the research and the results of the effects of meteorological conditions to the aviation operations and aviation psychology only for rain, fog, snow, low cloud height, in a series of 19 Annexes. The effects of geomagnetic storms on the aviation were offered by the Aviation Industry of the United Kingdom in 2013 for the first time.

Associated with solar coronal mass ejections, coronal holes, or solar flares, a geomagnetic storm is caused by a solar wind shock wave which typically strikes the Earth's magnetic field 24 to 36 hours after the event. The Dst or disturbance storm time index is a measure of geomagnetic activity used to assess the severity of magnetic storms. Another index that measures the magnitude of the geomagnetic storm is the $K p$-index. $K p$-index is an indicator of disturbances in the Earth's magnetic field by getting daily data for every 3 hours. The scale of numbers of $K p$-index changes from 0 (quiet) to 9 (violent). Geomagnetic activity is crucially affected by the 11 - years period of solar activity cycle and 22 years period of the solar magnetic cycle.

During periods of strong geomagnetic disturbances, indisposition, weakness, and presence of indistinct localized headaches are the most distinct disorders, while disorganization of functional activity of the cortex of the human brain, which is likely to be connected with dysfunction of negative subcortical systems, with disbalance of its ascending synchronizing and desynchronizing influences, is another important disorder. Geomagnetic storms mainly affect the right hemisphere of the brain, and visual, audial and sensual variations in the brain cortex are also changed promptly during this stormy period. The lesions caused by damage of the temporal cortex impair the ability to recognize the distinctions between different perceptual stimuli and reduce the ability to detect partial types of visual information.

When we think that the right hemisphere is responsible for cognitive functions like visual-spatial material, the ability to compute the visual and spatial, which is already essential to the flight, will be affected. In this case, the pilot may forget important accounts, make miscalculations and lose the ability to assess events carefully. Here, if the pilot's cognitive and personality traits are sufficiently 
developed, he/she will have an ability to reduce these effects. If these effects cannot be reduced and he/she does not have the emotional regulation capacity to overcome his fears, he/she can hesitate, panic and be unable to perform. The major nervous tension may distort the pilot's perception of time.

When the nervous system that brings information to the brain is affected; Heart infarcts, seizure conditions, mental disorders due to the nervous system are seen, also, these disorders will become even more uncomfortable as the duration of radiation becomes longer. In such situations where it is necessary to make a decision urgently and suddenly, geomagnetic storm induces an increment in blood pressure and heart pulsation, an increase in respiratory rate, the expansion of the pupil of the eye, an increase in sweating, a decrease in the saliva secretion, generation of more energy depending on the increase in the amount of sugar in the blood, an increase the coagulation factors, causes the blood to head towards to the brain and striated muscles from the digestive organs. Changes in vision, hearing and body senses are important elements of brain being affected by the geomagnetic storms. In such situations, the motor cortex will be effective in making the body more sensitive and requiring detailed muscle coordination.

Aviation psychology trials have begun to gain momentum in the United Kingdom in 2013; however, Turkey has yet to check the aircraft accident reports arising from the meteorological and astronomical causes, neither has it studied these effects on subjects in more established research laboratories. Furthermore, because Turkey is a country located in the mid-latitudes, pilots cannot demonstrate the effects of geomagnetic storms in the same way with the pilots who live in the region of high latitudes and polar, for this reason, laboratory studies needs to accelerate as soon as possible. Therefore, I hope this article will lead this study. In case these applications come to life, this experiment will performed for the first time. The kind of work that can be done in the future:

First, a laboratory environment in which all the physical parameters of the geomagnetic storm exist should be established with scientists from science and engineering fields and clinicians. The test subjects must be selected according to the cognitive psychology and personality psychology test results, different age, and physical conditions, etc. both for the military and the civil aviation pilots. This will be the first classification. The second classification should be done according 
to the type of aircraft that pilots use. In environments corresponding to different geomagnetic storm severities, people are tested, and a separate classification must be made according to the reactions they give when they are exposed to different intensity values between 0 and 9 in our third classification. Depending on the duration of the effect of geomagnetic storms from a few hours to several days, a different classification should be made according to the duration periods in which they are exposed in the fourth classification. Immediately after each test run, pilots should undergo neurophysiological testing with the requisite medical and psychological examination. Thus, the psychological and physiological changes can be observed in the pilot before and after the test.

The pilot and flight crew flying at high latitudes will experience the effect of the geomagnetic storm directly; whereas the response of the pilot and flight crew, using the aircraft in the middle latitudes, such as Turkey, to these effects can be measured only with tests in the laboratory environment. This hypothesis is of special importance, as these experiments will be applied for the first time in aviation psychology literature.

\section{Kaynakça}

\section{Kitaplar}

Berkow, R. et al. (1992). The Merck Manual of Diagnosis and Therapy. (Çev. Ed. Murat Keklikoğlu ve Muzaffer Tuzcu), Merck Research Laboratories, MERCK \& CO., INC. Rahway, N.J.

Cannon, P. S., Angling, M., Barclay, L., Curry, C., Dyer, C., Edwards, R. et al. (2013a). Extreme Space Weather: Impacts on Engineered Systems - a Summary Rep. ISBN 1-903496-96-9 Royal Academy of Engineering, London, UK.

Cannon, P. S., Angling, M., Barclay, L., Curry, C., Dyer, C., Edwards, R. et al. (2013b). Extreme Space Weather: Impacts on Engineered Systems Rep.ISBN 1-903496-95-0 Royal Academy of Engineering, London, UK.

Carlson, N. R. (2014). Foundations of Behavioral Neuroscience. (Çev. Ed. Muzaffer Şahin), İstanbul: Nobel Yayınevi. 
Cüceloğlu, D. (1999). İnsan ve Davranışı, Psikolojinin Temel Kavramları. İstanbul: Remzi Kitabevi.

Çetingüç, M. (2016). Havacılık ve Uzay Psikolojisi. İstanbul: Nobel Akademik Yayınc1l1k.

Gagarin, Y. ve Lebedev, V. (1984). Uzay ve Psikoloji. (Çev. Sibel Özbudun), İstanbul: Süreç Yayınevi.

Gegenfurthner, K. R. (2005). Beyin ve Algılama. (Çev. Barış Konukman), İstanbul: İnk1lâp Kitapevi.

National Transportation Safety Board (2005). Risk Factors Associated with Weather-Related General Aviation Accidents. Safety Study NTSB/SS05/01. Washington, DC.

Öktem, Ö. (2013). Davranı̧ssal Nörofizyolojiye Giriş. İstanbul: Nobel Tıp Kitapevi.

Ragan, K. M. (2010). The Warfighters of Today: Personality and Cognitive Characteristics of Rated Fighther Pilots in the United States. (Doktora Tezi). Florida State University Library.

\section{Makaleler}

Babayev, E. S. and Allahverdiyeva, A. A. (2005). Geomagnetic Storms and Their Influence on the Human Brain Functional State. Revista CENIC Ciencias Biológicas, 36, 1-8.

Burton, R. K., McPherron, R. L. ve Russell, C. T. (1975). An Empirical Relationship Between Interplanetary Conditions and Dst. Journal of Geophysical Research, 80, 4204-4214.

Ersoy, E. ve Karal, Ö. (2012). Yapay Sinir Ağları ve İnsan Beyni. İnsan ve Toplum Bilimleri Araştırmaları Dergisi, 1(2), 188-205.

Göker, Ü. D. (2008). The Importance of Heat Conduction and Viscosity in Solar Corona and Comparison of Magnetohydrodynamic Equations of One-Fluid and Two-Fluid Structure in Current Sheet. Sun and Geosphere, 3(1), 52-56. 
Göker, Ü. D. (2012). Magnetohydrodynamic Study of Shock Waves in the Current Sheet of a Solar Coronal Magnetic Loop. New Astronomy, 17, 130-136.

Göker, Ü. D., Gigolashvili, M. Sh. ve Kapanadze, N. (2017). Solar Spectral Irradiance Variability of Some Chromospheric Emission Lines Through the Solar Activity Cycles 21-23. Serbian Astronomical Journal, 194, 7186.

Göker, Ü. D., Singh, J., Nutku, F. ve Priyal, M. (2017). Temporal Variations of Different solar Activity Indices Through the Solar Cycles 21-23. Serbian Astronomical Journal, 195, 59-70.

Gulyaeva, T. L. ve Stanislawska, I. (2008). Derivation of a Planetary Ionospheric Storm Index. Annales Geophysicae, 26, 2645-2648.

Koonce, J. M. (1984). A Brief History of Aviation Psychology. Human Factors, 26(5), 499-508.

Mertens, C. J., Kress, B. T., Wiltberger, M, et al. (2010). Geomagnetic Influence on Aircraft Radiation Exposure During a Solar Energetic Particle event in October 2003. Space Weather, 8, S03006- S03022.

O’Brien, T. P. ve McPherron, R. L. (2000). An Empirical Phase Space Analysis of Ring Current Dynamics: Solar Wind Control of Injection and Decay. Journal of Geophysical Research, 105, 7707-7719.

Timoçin, E., Ünal, İ., Tulunay, Y. ve Göker, Ü. D. (2018). The Effect of Geomagnetic Activity Changes on the Ionospheric Critical Frequencies (foF2) at Magnetic Conjugate Points. Advances in Space Research, 62, 821-828.

\section{Yayımlanmamış çalışmalar}

Göker, Ü.D. (Baskıda). Temporal Modelling of Chromospheric Emission Lines for Solar Spectral Irradiance Through the Solar Activity Cycles 2123, Comptes Rendus de l-Académie Bulgare des Sciences.

Timoçin, E., Ünal, İ. ve Göker, Ü. D. (Baskıda). A Comparison of IRI-2016 foF2 Predictions with the Observations at Different Latitudes During Geomagnetic Storms, Geomagnetism and Aeronomy. 


\section{Yazarı belli olmayan web sitesi makalesi}

http://www.ises-spaceweather.org/ (Space Weather Effects in Regard to International Air Navigation ).

http://www.icrp.org/icrpaedia/limits.asp (Dose Limits Help Ensure That No Person is Exposed to an Excessive Amount of Ionising Radiation in Normal, Planned Situations). 